\title{
The preservation effect and mechanism of gelatin on golden pompano (Trachinotus blochii) fillets during cold storage
}

\author{
Peiyu WEI ${ }^{1}$, Jun $\mathrm{CAO}^{1}$, Xuanri SHEN ${ }^{1}$, Chuan $\mathrm{LI}^{1 *}$
}

\begin{abstract}
The effect of different concentrations of gelatin $(0 \%, 2.5 \%$, and $5 \%)$ and vacuum packaged on the preservation of golden pompano (Trachinotus blochii) fillets stored at $4{ }^{\circ} \mathrm{C}$ was studied over 14 days. The results suggested that both the gelatin groups $(2.5 \%$ and $5 \%)$ showed a reduction in deterioration of colour, drip loss and texture compared to the control group (0\%). In addition, the gelatin coating caused a slower reduction in the freshness indexes of the fish, such as total volatile base nitrogen (TVB-N), thiobarbituric acid reactive substances (TBARS), total viable counts and $\mathrm{pH}$. During a certain storage period, the gelatin notably prevented the deterioration of the golden pompano fillet at $4{ }^{\circ} \mathrm{C}$. The $5 \%$ gelatin group showed the best effect on preserving the freshness indexes. Thus, the application of gelatin as a preservative is highly prospective for the preservation of fish fillets.
\end{abstract}

Keywords: gelatin; cold storage; preservation; golden pompano; fillet.

Practical Application: Gelatin coating treatment could maintain the quality and safety of golden pompano fillets.

\section{Introduction}

The golden pompano (Trachinotus blochii) is one of the major marine cultured fish species in China and Southeast Asian countries. It is one of the most popular fish among consumers because of its tenderness, delicious taste and few intermuscular bones. Golden pompano provides rich nutritional profile and edible value (He et al., 2019). Recently, consumers have been paying more attention to the freshness of aquatic products, and the proportion of fish sales has been increasing rapidly. At present, traditional freshness-keeping methods, including freezing, chilling, radiation, and ultra-high pressure, have been studied and applied. The technology of low-temperature preservation is one of the most common methods used for aquatic products, with the advantages of low cost and maintaining the original properties of fresh golden pompano. In addition, suitable packing and preservatives have been used on fish products to improve quality and increase the shelf life of the fresh fish during cold storage.

Gelatin is a natural biological macromolecule extracted from the skin, bones and connective tissue of animals (Wang et al., 2019). Gelatin has the properties of strong water-binding capacity, good film-forming ability, high viscosity of solution, low gelling and melting temperatures, and high reactivity of its side chain group (Ahmad et al., 2017). Currently, edible coating was developed to preserve the quality and prolong the shelf life of fish food (Feng et al., 2016). For example, gelatin coatings have been developed to serve as a barrier for water and oxygen to prevent the food surface from becoming contaminated (Chen et al., 2016), resulting in reduced water loss, lipid oxidation and growth of bacteria. In addition, the enzymatic hydrolysate of gelatin has shown an antioxidant effect (Hosseini et al., 2017). Catfish gelatin has acted as an antimicrobial coating and has been used to prolong the shelf life of fresh white shrimp (Penaeus vannamei) (Jiang et al., 2010). Gelatin, incorporated with other techniques, has also been reported to generally enhance the tenderness of fish (Bekhit et al., 2014). Therefore, it is feasible to apply gelatin to keep golden pompano fresh.

In this study, the effect of different concentrations of gelatin $(0 \%, 2.5 \%$, and $5 \%)$ along with vacuum packaging treatment was evaluated via freshness indexes, such as sensory characteristics (drip loss, colour, and texture), $\mathrm{pH}$ value, TVB-N, lipid oxidation and microorganism growth, in golden pompano during storage at $4{ }^{\circ} \mathrm{C}$. The purpose of this study was to determine whether treatment involving gelatin solution immersion and coating could effectively improve the quality of fish and extend the shelf life of golden pompano. This study provides basic experimental data and new ideas for the application of gelatin in aquatic product preservation.

\section{Materials and methods}

\subsection{Fish samples and preparation}

Fresh golden pompano (weight of $500 \pm 100 \mathrm{~g}$ ) was purchased from the local market in Haikou, China. The fish fillets were cut into pieces that were approximately $2 \mathrm{~cm}$ thick with a weight of approximately $30 \mathrm{~g}$. Subsequently, samples were randomly assigned into three groups, including a control group (uncoated, $0 \%$ ) and two treatment groups with coating concentrations of $2.5 \%$ and $5 \%$ of gelatin (Aladdin, China). Gelatin solution was swelled for $6 \mathrm{~h}$ in distilled water at room temperature, after being heated at $65^{\circ} \mathrm{C}$ in water bath for $20 \mathrm{~min}$ and cool to room temperature

${ }^{1}$ Hainan Provincial Engineering Research Centre of Aquatic Resources Efficient Utilization in the South China Sea, Key Laboratory of marine Processing of Haikou, College of Food Science and Technology, Hainan University, Haikou, China

*Corresponding author: lichuan@hainanu.edu.cn 
(Wang et al., 2019). For each coated sample, fillets were immersed for $5 \mathrm{~min}$ in the coating solution. Under the same conditions, the fish fillets of the control group were immersed in distilled water. Then, the fillets were removed, drained using sterile gauze, packed into vacuum bags and stored at $4{ }^{\circ} \mathrm{C}$ for 14 days.

\subsection{Determination of drip loss}

The samples were taken out of their packages. The mass of each sample after storage was obtained by blotting exudate with a paper towel. The results were calculated according to a previous study (Chong et al., 2015).

\subsection{Determination of colour}

The colour of the fillets was measured by a colourimeter (CR-10, Konica Minolta, Japan). For the colorimeter results, the $L^{*}, a^{*}$, and $b^{*}$ values represent the brightness, redness and yellowness of the fish colour, respectively. $\Delta \mathrm{E}$ was calculated by the following formula (equation 1):

$$
\Delta E=\sqrt{\left(L-L^{\prime}\right)^{2}+\left(a-a^{\prime}\right)^{2}+\left(b-b^{\prime}\right)^{2}}
$$

where $L^{\prime}, a^{\prime}$ and $b^{\prime}$ denote values at 0 days of storage time and $L$, $a$ and $b$ denote values at 2 days of storage time.

\subsection{Determination of hardness and elasticity}

A texture analyzer (CT3, Brookfield, USA) was developed to objectively measure the hardness and elasticity of the golden pompano samples. To carry out the measurement, a flat bottom cylindrical probe with a $6 \mathrm{~mm}$ diameter (TA41) was used as the load cell. The samples were measured at a testing speed of $1 \mathrm{~mm} / \mathrm{s}$, a compression distance of $4 \mathrm{~mm}$ and a trigger point load of $7 \mathrm{~g}$.

\subsection{Determination of $p H$}

Approximately $3 \mathrm{~g}$ of the fish sample was homogenized. Then, $27 \mathrm{~mL}$ of $0.1 \mathrm{~mol} / \mathrm{L} \mathrm{KCl}$ solution was added, and the mixture was stirred. The mixed solution was filtered, and the $\mathrm{pH}$ was determined with a digital $\mathrm{pH}$ meter (MP511, Sanxin Instrumentation, Inc., Shanghai, China).

\subsection{Determination of TBARS value}

The TBARS values of the samples were measured according to the instructions of a Malondialdehyde (MDA) Assay Kit (TBA method) (Jiancheng Bioengineering, Nanjing, China).

\subsection{Determination of TVB-N}

TVB-N value was estimated by an auto-Kjeldahl analyser (K9840, Hanon, Jinan, China) via the automatic Kjeldahl method.

\subsection{Determination of total microbial counts}

Fillet samples were homogenized with $0.1 \%$ peptone water, and serial dilutions were made. Total microbial counts were determined after incubation at $37^{\circ} \mathrm{C}$ for $24 \mathrm{~h}$ using plate count agar (PCA, XK97-A, Yalien, Beijing).

\subsection{Statistical analysis}

The statistical analysis of the experimental data was carried out using SPSS Statistics 20.0 software (SPSS, Inc., Chicago, IL). The differences among various groups were evaluated by an analysis of variance (ANOVA) using Duncan's test. The significance level was set to $P<0.05$. All measurements were repeated three times for each sample, and mean values \pm Standard Error of Mean (SEM) were denoted for each sample.

\section{Results and discussion}

\subsection{Drip loss}

During storage, the drip loss of the fillet was caused by fish surface drying, microbial action, degradation of fish muscle, proteolysis and other factors. As shown in Table 1, the drip loss value of all the samples increased with storage time. The change range of drip loss for gelatin-treated samples was less than that of the control group, and the change in drip loss in the 5\% gelatin group was slower than that in the $2.5 \%$ gelatin group. The drip loss of the $5 \%$ gelatin group was significantly lower than that of the control group at storage day 3 and day $6(P<0.05)$. The possible reason was that the gelatin contains hydrophobic amino acids (such as proline and leucine), which help to preserve the water and nutrients in the flesh. The water was blocked by a dense membrane formed by gelatin on the surface of the fish (Limpisophon et al., 2009), prolonging the freshness-keeping of the fillet. However, after 6 days, there was no obvious difference between the control group and the gelatin groups $(P>0.05)$. During this period, numbers of microorganisms grew in the fillets containing abundant protein, which accelerated the decomposition of the muscle of the fish and the denaturation of myosin. As a result, the hydration capability of the gelatin was decreased. Therefore, the gelatin coatings effectively decreased the drip loss of fish fillets (Tongnuanchan et al., 2016).

\subsection{Colour}

The $\Delta \mathrm{E}$ value of the fillet in the control group changed notably after 8 days, increasing from 7.05 to 14.29 (Table 2). The $\Delta \mathrm{E}$ value of the gelatin groups increased slowly, demonstrating a significantly $(P<0.05)$ different compared with the control group from day 10 to day 14 . In addition, the $\Delta \mathrm{E}$ value of the $5 \%$ gelatin group was lower than that of the $2.5 \%$ gelatin group after 6 days of storage. Gelatin has the characteristics of oxygen resistance and good film-forming properties (Abdelhedi et al.,

Table 1. Effect of gelatin on the drip loss (\%) of golden pompano fillets stored in vacuum packing at $4{ }^{\circ} \mathrm{C}$ for 14 days.

\begin{tabular}{cccc}
\hline \multirow{2}{*}{ Storage time/d } & \multicolumn{3}{c}{ gelatin concentration \% } \\
\cline { 2 - 4 } & Control $(0)$ & 2.5 & 5 \\
\hline 3 & $1.88 \pm 0.23^{\mathrm{b}}$ & $1.46 \pm 0.27^{\mathrm{ab}}$ & $1.00 \pm 0.13^{\mathrm{a}}$ \\
6 & $3.01 \pm 0.08^{\mathrm{b}}$ & $2.56 \pm 0.31^{\mathrm{ab}}$ & $2.14 \pm 0.21^{\mathrm{a}}$ \\
9 & $5.32 \pm 0.19$ & $4.55 \pm 0.32$ & $4.91 \pm 0.04$ \\
12 & $9.90 \pm 0.90$ & $8.77 \pm 0.38$ & $8.75 \pm 0.31$ \\
14 & $10.42 \pm 0.94$ & $9.99 \pm 0.65$ & $9.85 \pm 0.65$ \\
\hline
\end{tabular}

Results are expressed as the means $\pm \operatorname{SEM}(n=3)$. Values with different superscripts are significantly different $(P<0.05)$. 
2018). Therefore, the preservation effect of the edible gelatin coating resulted from preventing oxygen transmission, protecting the fillet from oxidation. In this study, the higher concentration of gelatin formed a denser membrane and improved the oxygen resistance ability of the fillet. Thus, the colour $\Delta \mathrm{E}$ value of the $5 \%$ gelatin sample changed less than those of the other groups. Therefore, the results indicated that gelatin effectively maintained the colour of the fish fillet.

\subsection{Change in texture}

Changes in golden pompano texture profiles, including hardness and elasticity, determine the marketability of such products (Rodríguez et al., 2016). The structure of the connective tissue in its original state develops into a disordered and loose state during cold storage, with myofibrillar fragmentation and proliferation of specific spoilage bacteria on the surface of the fillet (Li et al., 2013). Thus, the gradual decrease in texture (elasticity and hardness) of the fish was noticeable after 14 days of storage.

The elasticity of the gelatin groups decreased more slowly than that of the control group (Figure 1A). The elasticity of the $2.5 \%$ gelatin group and the $5 \%$ gelatin group ( 2.60 to $2.41 \mathrm{~mm}$ ) between 12 and 14 days was significantly higher than that of the

Table 2. Effect of gelatin on $\Delta \mathrm{E}$ values of golden pompano fillets during cold storage.

\begin{tabular}{cccc}
\hline \multirow{2}{*}{ Storage time/d } & \multicolumn{3}{c}{ gelatin concentration \% } \\
\cline { 2 - 4 } & Control $(0)$ & 2.5 & 5 \\
\hline 2 & $4.54 \pm 0.16^{\mathrm{c}}$ & $3.86 \pm 0.78^{\mathrm{b}}$ & $2.75 \pm 0.24^{\mathrm{a}}$ \\
4 & $5.35 \pm 0.92$ & $4.27 \pm 0.21$ & $4.53 \pm 0.20$ \\
6 & $6.51 \pm 1.82$ & $4.40 \pm 1.08$ & $5.08 \pm 1.31$ \\
8 & $7.05 \pm 1.89$ & $6.24 \pm 0.99$ & $5.97 \pm 1.11$ \\
10 & $11.47 \pm 0.35^{\mathrm{b}}$ & $7.26 \pm 0.99^{\mathrm{a}}$ & $6.01 \pm 1.08^{\mathrm{a}}$ \\
12 & $11.32 \pm 1.00^{\mathrm{b}}$ & $5.73 \pm 1.18^{\mathrm{a}}$ & $6.45 \pm 1.03^{\mathrm{a}}$ \\
14 & $14.29 \pm 1.58^{\mathrm{b}}$ & $7.30 \pm 0.23^{\mathrm{a}}$ & $6.47 \pm 1.23^{\mathrm{a}}$ \\
\hline
\end{tabular}

Results are expressed as the means \pm SEM $(n=3)$. Values with different superscripts are significantly different $(P<0.05)$.

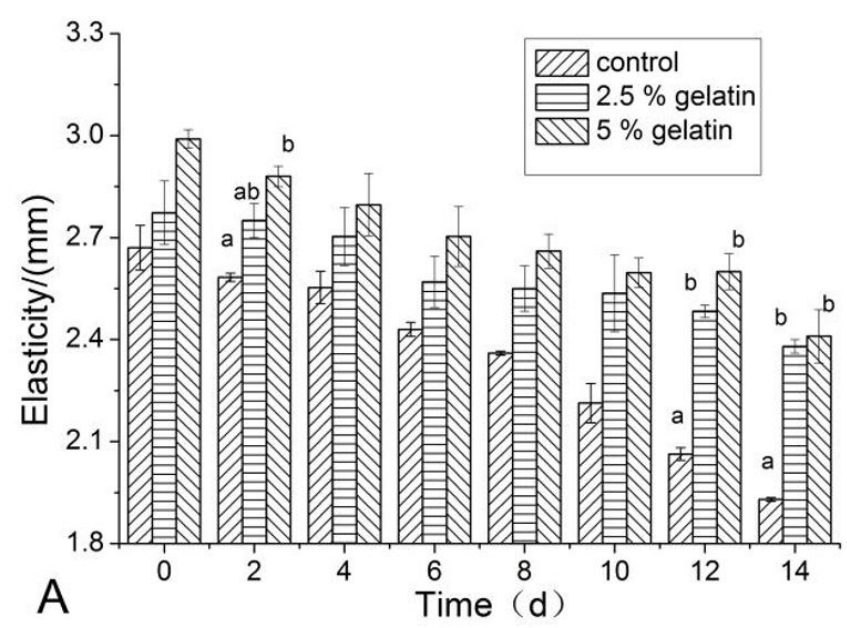

control group (2.06 to $1.93 \mathrm{~mm}, P<0.05$ ). The hardness of the fillets showed the same change trend as elasticity (Figure 1B).

Therefore, the coating of gelatin had a protective effect on the fish sample and reduced the deterioration of texture, which was due to the good characteristics of the membrane formed by the gelatin. The higher value of texture in the $5 \%$ group compared to the $2.5 \%$ group was due to an improvement in the gel strength and hardness of the gelatin as the concentration increased (Yang \& Wang, 2009).

\section{$3.4 \mathrm{pH}$}

Complex biological reactions still take place in the bodies of dead fish. The $\mathrm{pH}$ of fish gradually decreases with the accumulation of lactic acid caused by biophysiological activities in the rigour stage (Zhang et al., 2018). Subsequently, the fish becomes soft and enters the stage of decay and autolysis until ATP is completely decomposed. During this time, the protein and other nitrogen-containing substances may be decomposed into basic substances because of the action of microorganisms and proteinase, which leads to an increased $\mathrm{pH}$ of the fish sample (Volpe et al., 2015). In this study, the $\mathrm{pH}$ values of samples undergoing different treatments showed a V-type distribution trend (Figure 2A). At day 2, the $\mathrm{pH}$ values of the control, $2.5 \%$ and $5 \%$ gelatin groups were 5.55, 6.14 and 6.21 , respectively. However, the $\mathrm{pH}$ change trend of the gelatin group was significantly slower compared to that of the control group at $0-12$ days $(P<0.05)$. Interestingly, the $\mathrm{pH}$ value of the $2.5 \%$ gelatin group was significantly higher than that of the $5 \%$ gelatin group at day $14(P<0.05)$. Therefore, the $\mathrm{pH}$ of the $5 \%$ gelatin group was steadier than the $\mathrm{pH}$ values of the $2.5 \%$ gelatin and control groups.

\subsection{TBARS}

Lipids are one of the most important chemical indicators for assessing the quality of fish. The TBARS method was used to evaluate the effectiveness of the antioxidants in preventing

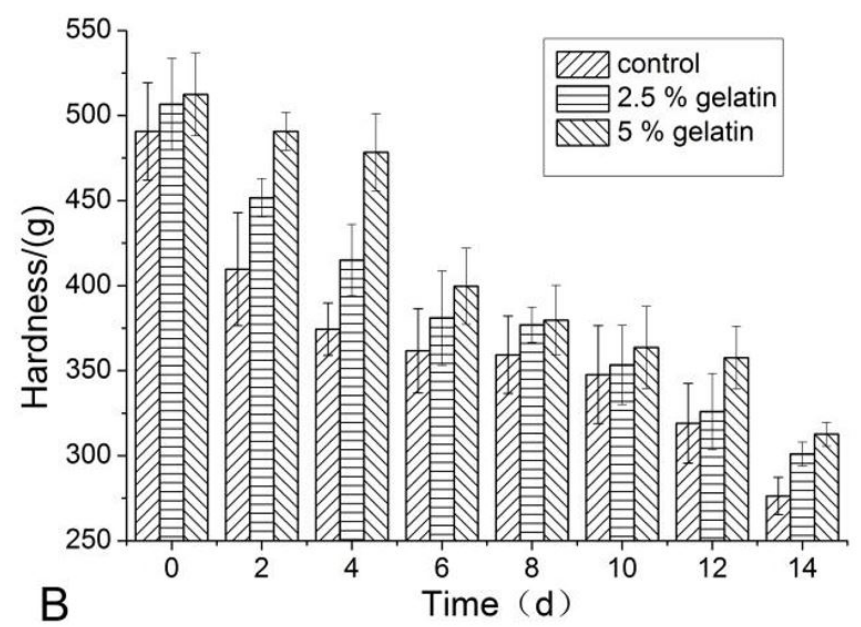

Figure 1. Effect of gelatin on the elasticity (A) and hardness (B) of golden pompano fillets stored in vacuum package at $4{ }^{\circ} \mathrm{C}$ for 14 days. Results are expressed as the means \pm SEM $(n=3)$. Values with different superscripts are significantly different $(P<0.05)$. 
oxidative degradation of lipids (Gallego et al., 2016). The increasing trend of TBARS in the gelatin groups was significantly lower than that in the control group (Figure 2B). However, the difference in TBARS values in the gelatin group was not obvious, and the change was slow from day 0 to 8 of storage. After 8 days, the TBARS value of the $2.5 \%$ gelatin group increased significantly faster compared with that of the $5 \%$ gelatin group over time. The TBARS value of the 5\% gelatin group from day 10 to 14 $(0.21$ to $0.41 \mathrm{mg} / \mathrm{kg})$ was significantly lower than that of the control group (0.48 to $1.33 \mathrm{mg} / \mathrm{kg}, P<0.05)$. The increased TBARS value was possibly attributed to the partial dehydration of the fish caused by microbial propagation and the increased oxidation of lipids (Kilincceker et al., 2009). However, the good membrane formation of gelatin, along with the synergistic effect of vacuum packaging as a formidable barrier to oxygen, reduced lipid oxidation (Gallego et al., 2016). In this study, the membrane formed by $5 \%$ of gelatin was denser than that formed by $2.5 \%$ of gelatin, leading to better oxygen insulation and inhibited oxidation of lipids.

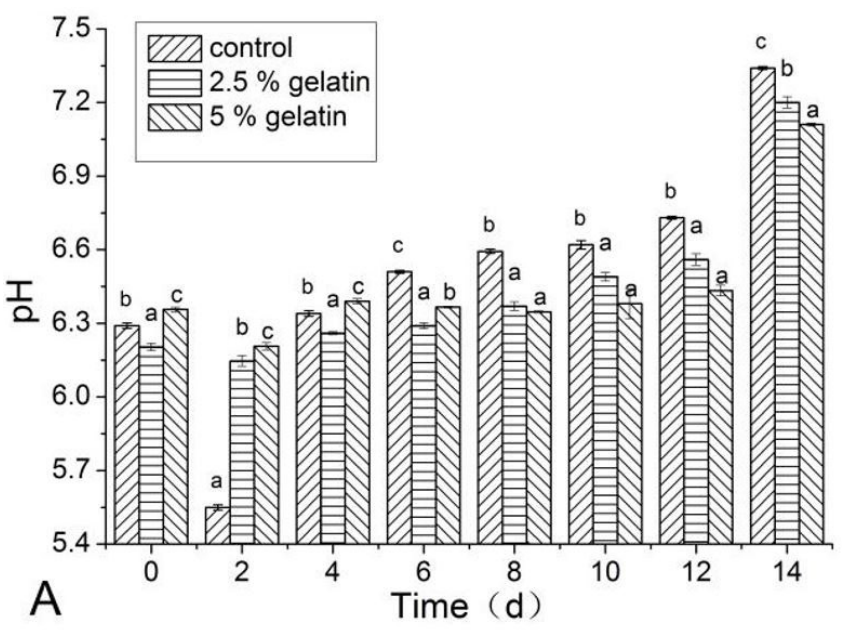

\subsection{TVB-N}

During storage, fish fillets decompose into basic nitrogen-containing substances such as ammonia, amines, other volatile bases and obnoxious odours, which are called TVB-N (Duan et al., 2010). The accumulation of TVB-N is closely related to enzymatic activity and microbial propagation (Hui et al., 2016). The TVB-N value of the golden pompano fillets increased with the prolongation of storage time (Figure 3A). However, the reduced deterioration of protein in groups treated with gelatin had a better effect than that of the control group. The TVB-N value of the control group increased to a higher value of $15.77 \mathrm{mg} / 100 \mathrm{~g}$ compared to the values of the gelatin groups, which were $13.97 \mathrm{mg} / 100 \mathrm{~g}$ $(2.5 \%)$ and $12.48 \mathrm{mg} / 100 \mathrm{~g} \mathrm{(5 \% )}$ at day 14 . However, it should be noted that the much lower value of TVB-N in the gelatin group was associated with the membrane formation of gelatin, which slowed down the propagation of microorganisms and enzyme activity at a low temperature.

Figure 2. Effect of gelatin on the $\mathrm{pH}(\mathrm{A})$ and TBARS value (B) of vacuum-packaged golden pompano fillets during cold storage. Results are expressed as the means \pm SEM $(n=3)$. Values with different superscripts are significantly different $(P<0.05)$.
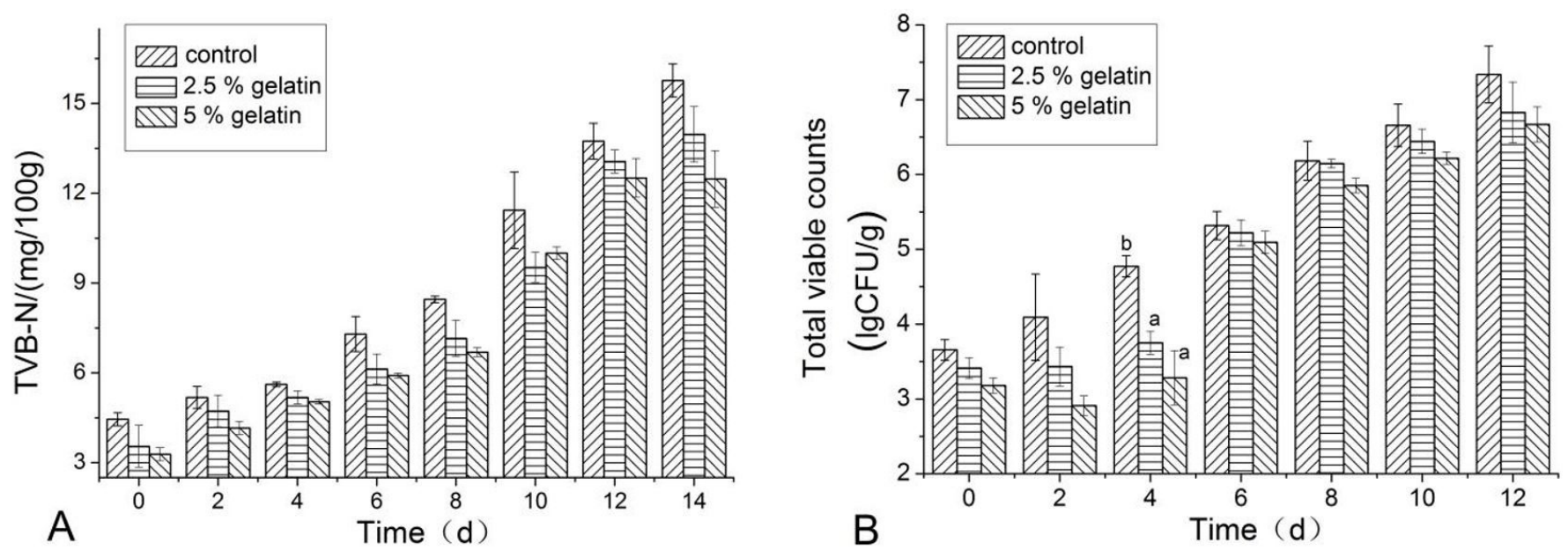

Figure 3. Effect of gelatin on the TVB-N value (A) and total viable counts (B) of vacuum-packaged golden pompano fillets during cold storage. Results are expressed as the means $\pm \operatorname{SEM}(n=3)$. Values with different superscripts are significantly different $(P<0.05)$. 


\subsection{Microbiological analyses}

The spoilage of golden pompano was mostly attributed to microbial activity. A total microbial number of $7 \mathrm{log} \mathrm{CFU} / \mathrm{g}$ was defined as an indicator of the spoilage degree of the fish (Manju et al., 2007). In this study, the total number of microbes in all groups showed an increasing trend over the storage time (Figure 3B). On day 12, the total number of microbes in the control group increased to $7.34 \mathrm{log} \mathrm{CFU} / \mathrm{g}$, reaching a serious point of spoilage and deterioration. In contrast, the microbial counts of the $2.5 \%$ gelatin group and the $5 \%$ gelatin group were $6.83 \log \mathrm{CFU} / \mathrm{g}$ and $6.67 \log \mathrm{CFU} / \mathrm{g}$, respectively. Lower microbial counts in the gelatin groups compared with the control group were detected during storage, and these lower microbial counts were particularly significant at day $4(P<0.05)$. Compared to the control treatment, the gelatin coating inhibited the growth of microbes, but there was no notable difference between the two gelatin groups. This lack of difference is possibly because the gelatin had no effective antimicrobial capacity (Feng et al., 2016). In this study, vacuum packing inhibited aerobic bacteria from proliferating during cold storage. In addition, the properties of the gelatin membrane as a barrier against oxygen transfer reduced the reproduction and metabolism of microorganisms (Abdelhedi et al., 2018). The membrane formed with the higher gelatin concentration was more stable, which resulted in an increased antimicrobial effect of the $5 \%$ gelatin treatment compared to the $2.5 \%$ gelatin treatment.

\section{Conclusion}

The gelatin-coated groups demonstrated a slower deterioration of colour and sensory quality. There were also beneficial effects on the loss of drip, $\mathrm{pH}$ and texture in the gelatin group compared with the control group. In addition, the gelatin, especially the high dose, effectively reduced protein decomposition and lipid oxidation and inhibited microbial growth. Overall, the best effect of preserving the quality of fish was observed in the $5 \%$ gelatin group. Therefore, the results indicated that gelatin coating used in the preservation of fish fillets not only could maintain the quality of aquatic products but also could improve the comprehensive utilization of by-products of aquatic product processing, reducing the amount of wasted resources. In conclusion, the application of gelatin to preserve fresh fillet products could be highly prospective.

Although gelatin presented good preservation effect, the limited mechanical property and non-obvious bacteriostatic effect are the main drawbacks of gelatin coatings in applications. With the advantages of different preservative, gelatin can be cooperated with other fresh-keeping materials to achieve better preservation effect.

\section{Acknowledgements}

This work was supported by fund of National Natural Science Foundation of China (31760484), Hainan Provincial Natural Science Foundation of China (319QN158), Key Project of Science and Technology of Haikou (2017051) and Scientific Research Foundation of Hainan University (KYQD1609).

\section{References}

Abdelhedi, O., Nasri, R., Jridi, M., Kchaou, H., Nasreddine, B., Karbowiak, T., Debeaufort, F., \& Nasri, M. (2018). Composite bioactive films based on smooth-hound viscera proteins and gelatin: Physicochemical characterization and antioxidant properties. Food Hydrocolloids, 74, 176-186. http://dx.doi.org/10.1016/j.foodhyd.2017.08.006.

Ahmad, T., Ismail, A., Ahmad, S. A., Khalil, K. A., Kumar, Y., Adeyemi, K. D., \& Sazili, A. Q. (2017). Recent advances on the role of process variables affecting gelatin yield and characteristics with special reference to enzymatic extraction: A review. Food Hydrocolloids, 63, 85-96. http://dx.doi.org/10.1016/j.foodhyd.2016.08.007.

Bekhit, A. A., Hopkins, D. L., Geesink, G., Bekhit, A. A., \& Franks, P. (2014). Exogenous Proteases for Meat Tenderization. Critical Reviews in Food Science and Nutrition, 54(8), 1012-1031. http://dx.doi.org/ 10.1080/10408398.2011.623247. PMid:24499119.

Chen, B.-J., Zhou, Y.-J., Wei, X.-Y., Xie, H.-J., Hider, R. C., \& Zhou, T. (2016). Edible antimicrobial coating incorporating a polymeric iron chelator and its application in the preservation of surimi product. Food and Bioprocess Technology, 9(6), 1031-1039. http://dx.doi. org/10.1007/s11947-016-1693-2.

Chong, J. X., Lai, S., \& Yang, H. (2015). Chitosan combined with calcium chloride impacts fresh-cut honeydew melon by stabilising nanostructures of sodium-carbonate-soluble pectin. Food Control, 53, 195-205. http://dx.doi.org/10.1016/j.foodcont.2014.12.035.

Duan, J., Jiang, Y., Cherian, G., \& Zhao, Y. (2010). Effect of combined chitosan-krill oil coating and modified atmosphere packaging on the storability of cold-stored lingcod (Ophiodon elongates) fillets. Food Chemistry, 122(4), 1035-1042. http://dx.doi.org/10.1016/j. foodchem.2010.03.065.

Feng, X., Bansal, N., \& Yang, H. (2016). Fish gelatin combined with chitosan coating inhibits myofibril degradation of golden pomfret (Trachinotus blochii) fillet during cold storage. Food Chemistry, 200, 283-292. http://dx.doi.org/10.1016/j.foodchem.2016.01.030. PMid:26830590.

Gallego, M., Gordon, M., Segovia, F., \& Almajano Pablos, M. (2016). Gelatine-Based antioxidant packaging containing Caesalpinia decapetala and tara as a coating for ground beef patties. Antioxidants, 5(2), 10. http://dx.doi.org/10.3390/antiox5020010. PMid:27043638.

He, C., Cao, J., Jiang, X., Wen, C., Bai, X., \& Li, C. (2019). Fatty acid profiles of triacylglycerols and phospholipids of sea-cage cultured Trachinotus blochii: A comparative study of head, viscera, skin, bone, and muscle. Journal of Food Science, 84(3), 650-658. http:// dx.doi.org/10.1111/1750-3841.14458. PMid:30714628.

Hosseini, S. F., Ramezanzade, L., \& Nikkhah, M. (2017). Nano-liposomal entrapment of bioactive peptidic fraction from fish gelatin hydrolysate. International Journal of Biological Macromolecules, 105(Pt 2), 1455-1463. http://dx.doi.org/10.1016/j.ijbiomac.2017.05.141. PMid:28552724.

Hui, G., Liu, W., Feng, H., Li, J., \& Gao, Y. (2016). Effects of chitosan combined with nisin treatment on storage quality of large yellow croaker (Pseudosciaena crocea). Food Chemistry, 203, 276-282. http://dx.doi.org/10.1016/j.foodchem.2016.01.122. PMid:26948615.

Jiang, M., Liu, S., Du, X., \& Wang, Y. (2010). Physical properties and internal microstructures of films made from catfish skin gelatin and triacetin mixtures. Food Hydrocolloids, 24(1), 105-110. http:// dx.doi.org/10.1016/j.foodhyd.2009.08.011.

Kilincceker, O., Dogan, İ. S., \& Kucukoner, E. (2009). Effect of edible coatings on the quality of frozen fish fillets. Lebensmittel-Wissenschaft + Technologie, 42(4), 868-873. http://dx.doi.org/10.1016/j.lwt.2008.11.003.

Li, T., Li, J., Hu, W., \& Li, X. (2013). Quality enhancement in refrigerated red drum (Sciaenops ocellatus) fillets using chitosan coatings 
containing natural preservatives. Food Chemistry, 138(2), 821-826. http://dx.doi.org/10.1016/j.foodchem.2012.11.092. PMid:23411183.

Limpisophon, K., Tanaka, M., Weng, W., Abe, S., \& Osako, K. (2009). Characterization of gelatin films prepared from under-utilized blue shark (Prionace glauca) skin. Food Hydrocolloids, 23(7), 1993-2000. http://dx.doi.org/10.1016/j.foodhyd.2009.03.014.

Manju, S., Jose, L., Srinivasa Gopal, T. K., Ravishankar, C. N., \& Lalitha, K. V. (2007). Effects of sodium acetate dip treatment and vacuumpackaging on chemical, microbiological, textural and sensory changes of Pearlspot (Etroplus suratensis) during chill storage. Food Chemistry, 102(1), 27-35. http://dx.doi.org/10.1016/j.foodchem.2006.04.037.

Rodríguez, A., Maier, L., Paseiro-Losada, P., \& Aubourg, S. P. (2016). Changes in Sensory and Physical Parameters in Chill-Stored Farmed Coho Salmon (Oncorhynchus kisutch). Journal of Aquatic Food Product Technology, 25(5), 633-643. http://dx.doi.org/10.1080/10 498850.2014 .913753$.

Tongnuanchan, P., Benjakul, S., Prodpran, T., Pisuchpen, S., \& Osako, K. (2016). Mechanical, thermal and heat sealing properties of fish skin gelatin film containing palm oil and basil essential oil with different surfactants. Food Hydrocolloids, 56, 93-107. http://dx.doi. org/10.1016/j.foodhyd.2015.12.005.

Volpe, M. G., Siano, F., Paolucci, M., Sacco, A., Sorrentino, A., Malinconico, M., \& Varricchio, E. (2015). Active edible coating effectiveness in shelf-life enhancement of trout (Oncorhynchusmykiss) fillets. Lebensmittel-Wissenschaft + Technologie, 60(1), 615-622. http:// dx.doi.org/10.1016/j.lwt.2014.08.048.

Wang, Q., Cao, J., Yu, H., Zhang, J., Yuan, Y., Shen, X., \& Li, C. (2019). The effects of EGCG on the mechanical, bioactivities, cross-linking and release properties of gelatin film. Food Chemistry, 271, 204-210. http://dx.doi.org/10.1016/j.foodchem.2018.07.168. PMid:30236668.

Yang, H., \& Wang, Y. (2009). Effects of concentration on nanostructural images and physical properties of gelatin from channel catfish skins. Food Hydrocolloids, 23(3), 577-584. http://dx.doi.org/10.1016/j. foodhyd.2008.04.016.

Zhang, X., Zhou, H., Chang, L., Lou, X., Li, J., Hui, G., \& Zhao, Z. (2018). Study of golden pompano (Trachinotus ovatus) freshness forecasting method by utilising Vis/NIR spectroscopy combined with electronic nose. International Journal of Food Properties, 21(1), 1257-1269. http://dx.doi.org/10.1080/10942912.2018.1440239. 